\title{
DOCUMENTO SÍNTESE DO FÓRUM \\ "OlHANDO PARA O FUTURO"
}

\section{Cíntia Okamura (Coord.), Alessandro de Oliveira Santos, Ana Maria Blanques, Anaruez Ferreira Morais, Carmem Beatriz Rodrigues Fabriani, Héctor Omar Ardans Bonifacino, Leila Aparecida Bomfim, Leila Vieira Kim, Nancy Ramacciotti de Oliveira e Ricardo Burg Mlymarz. \\ Laboratório de Psicologia Sócio-Ambiental e Intervenção-IPUSP}

O Fórum "Olhando para o Futuro" teve como objetivo proporcionar o intercâmbio entre os diversos setores da sociedade civil e as contribuições científico-intelectuais em torno da Psicologia Ambiental oferecidas no Simpósio Internacional Psicologia e Ambiente, bem como integrar as discussões sobre o tema às diversas problemáticas sócioambientais apresentadas por estes setores. É apresentado, como resultado, um documento síntese, elaborado para subsidiar uma Agenda de Pesquisa e Intervenção, norteado por três temas, elegidos pelos participantes do Fórum: Educação Ambiental e Psicologia Ambiental; Articulação Universidade, Estado e Sociedade; Estratégias Participativas de Planejamento.

Descritores: Psicologia ambiental. Planejamento ambiental. Educação ambiental.

$\mathrm{O}$ Fórum propiciou um intercâmbio de comunidades, institutos de pesquisa, organizações não governamentais, intelectuais e autoridades com as contribuições científico-intelectuais oferecidas no Simpósio Internacional. O resultado é este documento síntese que deverá subsidiar uma $A$ genda de Pesquisa e Intervenção.

1 Departamento de Psicologia Social e do Trabalho do Instituto de Psicologia da Universidade de São Paulo. Endereço eletrônico: lapsi@edu.usp.br 
Os participantes do Simpósio Internacional e agentes de setores da sociedade civil decidiram que haveria três temas norteadores das discussões. Dessa forma, foram constituídos os seguintes grupos de trabalho:

- Educação Ambiental e Psicologia Ambiental

- Articulação Universidade, Estado e Sociedade

- Estratégias Participativas de Planejamento

Cada grupo foi constituído por aproximadamente 20 pessoas. Estas se apresentaram a partir do vínculo com os respectivos espaços de trabalho e estudo e também a partir de suas identidades profissionais. Estavam presentes lideranças de organizações não governamentais, gestores de escolas públicas, gestores de secretarias municipais de governo, gerentes de empresa, assessores, pesquisadores e professores na área de Psicologia, graduandos e pós graduandos. No período final, houve apresentação dos resultados dos grupos.

Segue-se um resumo das principais conclusões.

\section{Educação Ambiental e Psicologia Ambiental}

A Educação Ambiental é o "fio condutor" para a construção de sociedades sustentáveis; portanto, há necessidade de reconhecimento de seu papel nas diferentes esferas sociais.

Da mesma forma, torna-se importante a definição do papel da Psicobgia Ambiental. Esta disciplina encontra-se em processo de estudo quanto ao entendimento de seu papel como atividade científica, definição de seu objeto de estudo e de suas fronteiras relativas, sendo esse o foco de discussão do próprio Simpósio Internacional.

É necessário uma orientação para uma prática de Educação Ambiental que inclua a noção de "Alfabetização Ecológica", fundada na compreensão da teia da vida e da importância da diversidade nessa rede, cujas conexões devem ser reconhecidas para evitar a degradação da vida no planeta. Para 
tanto, é importante se inserir nessa prática a dimensão ética: retomada de valores e resgate da humanização na formação dos indivíduos, de tal modo que a ênfase se transfira do pólo do egoísmo e individualismo para o pólo da solidariedade, cooperação e construção coletiva. Nesse contexto, a Psicologia Ambiental pode apresentar-se como fator primordial para $\mathrm{o}$ (re)conhecimento da teia da vida, de seu sentido holístico e de sua dinâmica. Portanto, a Psicologia Ambiental, pode contribuir para a formação de valores, para a busca do Ser e para a condução do indivíduo a novas linguagens relativas à dimensão da cidadania planetária.

É necessário estimular na prática da Educação Ambiental relações de compromisso e reciprocidade, em que todas as dimensões do mundo - íntima, interativa, social e biofísica - estão associadas entre si em termos de doação e recepção. Dessa forma, a Psicologia Ambiental pode contribuir orientando o trabalho, em conjunto com as subjetividades, com a interatividade e com as dinâmicas participativas dos grupos de pequeno, médio e grande porte, para a execução eficiente de projetos que respondam a demandas sócio-ambientais, uma vez que as atividades planejadas dependem sempre da presença de indivíduos e de grupos.

A Educação Ambiental deve ser um tema transversal, inter e transdisciplinar, inserido em todos os níveis educacionais (do ensino infantil, fundamental, médio, técnico e superior).

É necessário sistematizar os conhecimentos da Educação e Psicologia Ambiental para colocá-los a serviço das comunidades. Da mesma forma, há a necessidade de se adequar o saber importado e/ou globalizado às necessidades locais.

\section{Articulação Universidade, Estado e Sociedade}

A Universidade deve privilegiar uma política universitária e científica que estimule projetos de investigação associados a temáticas relevantes da esfera social. Desse modo seria possível produzir elementos teóricos e práti- 
cos capazes de contribuir para uma maior integração entre as funções do Estado, as necessidades da Sociedade e as funções da Universidade.

A Universidade deve estimular a investigação e o desenvolvimento de estratégias participativas de planejamento. A participação popular é condição fundamental para a construção do bem comum, ou seja, a tomada de decisão sobre o patrimônio material e não material da Terra. As estratégias participativas de planejamento constituem-se em ferramentas para a transformação da realidade social na direção do bem comum. Desse modo, deveriam ser utilizadas para fazer o diagnóstico da realidade social, levantar aspirações da população e também para ajudar a implementar soluções capazes de aproximar o ideal de bem comum da sua realização. A partir dessas estratégias seria possível influenciar a produção da consciência ambiental da população, de modo que todos pudessem perceber o ambiente de forma crítica e possível de ser transformado. A única maneira de não impor um modelo de sustentabilidade, silenciando outras possibilidades da relação ser humano-natureza, é a escuta do outro, sua participação. A participação popular é fundamental não só porque reduz a arbitrariedade envolvida na definição dos problemas que exigem solução nas formas de solucionar mas porque indica um caminho na definição de bem comum que, de fato, dá voz às diferentes concepções de bem comum.

\section{Estratégias Participativas de Planejamento}

A participação é um processo lento, demorado e histórico que se dá em diferentes níveis, como processo de aprendizado não linear, com avanços e recuos envolvendo muitos e diferentes atores - pessoas e instituições com diferentes interesses, em tomada de decisão a curto, médio e longo prazo. Não se restringe a reivindicações com o que é muitas vezes confundido. É um processo que gera transformações pessoais e transformações do trabalho, transformações que comportam diferentes significados. Pode ser advinda de fora, de agentes conscientizadores e chegar a ser efetiva em termos de poder público adquirindo modo próprio, desenvolvendo autonomia. 
Podemos identificar nos processos participativos de planejamento três tipos de ator: as empresas públicas ou privadas que tem projetos a serem empreendidos, a população e as assessorias ou mediadores para a realização desses projetos.

Os processos participativos ocorrem a partir de vínculos afetivos e emocionais com a causa, com os participantes, com os mediadores de grupos. Outra dimensão do vínculo afetivo é o vinculo consigo mesmo. O vínculo consigo mesmo pode ser também construído como ambiente interno do sujeito que participa. As aspirações vão se construindo e se delimitando no mesmo processo participativo e não a priori, por agentes externos ou instit uições externas. Mas, por outro lado, há também a necessidade de políticas públicas assertivas que se constituam a partir das necessidades da comunidade e que visem e orientem para objetivos mais profundos a longo prazo. Outro emergente do grupo aponta a necessidade de se lidar concomitantemente com o curto, médio e longo prazos, com objetivos que tragam resultados imediatos e com objetivos mais profundos.

Dentre as dificuldades enfrentadas nos processos de participação destaca-se o risco de frustração que pode estar associado à perda de credibilidade de quem chama à participação e às diferentes expectativas. Outra dificuldade diz respeito à cultura de resultados. Em todas as ações, há expectativas de resultados, entre os quais, a pressão pelos resultados econômicos. Os resultados trazem também a questão dos diferentes tempos. Os tempos carregam questões de valores e interesses dos diferentes atores. Em termos de dificuldades temos assim as diferenças de visão ou expectativas de resultados, tempos e valores. Essas diferenças revelam as diferenças de atores e interesses inerentes aos processos participativos. Nos interesses estão implicados os diferentes desejos e o problema da desejabilidade nas dimensões individual e coletiva. Há também o problema de se induzir a participação. As instituições e as diferentes instâncias de decisão são "de fora", não nascidas dos agentes que "deveriam" participar. As práticas participativas também podem conter uma cultura autoritária, onde se observam impotência e desejo de autoridade, práticas de submissão disfarçadas em práticas participativas, demandas de controle externo ao grupo. Podemos identificar ainda 
como dificuldades e riscos da participação os conflitos de autoria, desejo de autoridade, conflitos de apropriação dos resultados, reprodução de modelos autoritários criando obstáculos para autonomia dos participantes.

No que diz respeito ao que facilita ou ajuda os processos participativos de planejamento, foram apresentados, de forma superposta, dois enfoques quanto à estratégia de participação e técnicas de participação. Do ponto de vista da estratégia, destaca-se a promoção de experiências em que ocorrem transformações efetivamente. Tais transformações devem seguir a direção da autonomia, da cidadania e do compromisso dos atores envolvidos (conceitos que precisam ser compreendidos e explorados em termos dos diferentes significados que comportam). Do ponto de vista das técnicas que podem promover participação, destacam-se: mapeamento do contexto em termos de organizações e demandas, antes ou no início do processo; delimitação clara do alcance de resultados; bons processos de comunicação ajudam inclusive na obtenção de resultados em menor tempo; ajudar na expressão de vontades, desejos e sonhos; identificar organizações que tem valores de participação como cultura própria e desafiar para objetivos mais profundos; investir na formação do ator coletivo com o desenvolvimento da auto-estima e autoconhecimento; construir e utilizar instrumentos adequados como, por exemplo, a avaliação continuada e instrumentos de gestão das ações decididas.

Psicologia Ambiental, Psicologia Social, Psicologia Comunitária buscam olhar, nos processos participativos, como está sendo construído o destino das populações no Brasil e no mundo. Se o ambiente é entendido como construção do espaço objetivo e material realizado pelo sujeito, a psicologia ambiental poderia investigar a construção do ambiente como espaço simbólico e como essa construção pode se dar de forma participativa, interferindo e sendo interferida pelo ambiente de forma retroalimentadora.

Okamura, C. (Coord.), Santos, A. O., Blanques, A. M., Morais, A. F., Fabriani, C. B. R., Ardans, O., Bomfim, L. A., Kim, L. V., Oliveira, N. R., \& Mlymarz, R. B. (2005). A document synthesizing the forum "Looking At The Future". Psicologia USP, 16(1/2), 271-277. 
Abstract: The International Symposium culminated in a Forum that fostered the interchange of discussions about the themes approached in the previous days, with representatives from communities, research institutes, non-governmental organizations, intellectuals and authorities, divided into three groups, organized around the themes: Environmental Education and Environmental Psychology; articulation between University, State and Society; participative strategies of planning. The result of these meetings is synthesized in the present document, which aims at subsidizing an Intervention and Research Agenda.

Index terms: Environmental psychology. Environmental planning.

Environmental education.

Okamura, C. (Coord.), Santos, A. O., Blanques, A. M., Morais, A. F., Fabriani, C. B. R., Ardans, O., Bomfim, L. A., Kim, L. V., Oliveira, N. R., \& Mlymarz, R. B. (2005). Document synthese du forum “Envisageant Le Futur". Psicologia USP, 16(1/2), 271-277.

Résumé: Le Symposium International a culminé par un Forum qui a favorisé un échange de discussions sur les thèmes débattus les jours précédents avec des représentants de communautés, d'instituts de recherche, d'organisations non gouvernementales, d'intellectuels et d'autorités, divisés en trois groupes, organisés autour des thématiques: Éducation Environnementale et Psychologie de l'Environnement; articulation Université, État et Société; stratégies participatives de planification. Le résultat de ces rencontres est ce document synthèse dont la finalité est de subventionner un Programme de Recherche et d'Intervention.

Mots-clés: Psychologie de l'environnement. Planification de l'environnement. Éducation environnementale.

Recebido em 5.04.2004

Revisto e encaminhado em 23.02.2005

Aceito em: 07.03.2005 